\title{
RELASI ESTETIKA WAYANG DAN ESTETIKA AGAMA
}

Muh. Mukti

Fakultas Bahasa dan Seni Universitas Negeri Yogyakarta

Abstrak

Keberadaan budaya bangsa untuk sekarang ini, tidak selalu berjalan dengan estetika agama, wayang di antaranya. Oleh karena itu, perlu dilakukan pemikiran bagaimana wayang tersebut berjalan dengan estetika agama. Agar wayang berjalan dengan estetika agama, harus disambungkan dengan dakwah. Untuk keperluan itu, digunakan tasykil, yakni ajakan secara langsung kepada penonton untuk dakwah usai wayang. Wayang setelah disambungkan dengan dakwah, berubah jenisnya menjadi kesenian dakwah, terminologinya ganda: wayang, tasykil, dan dakwah, tuntunannya agama, dan bentuknya sambung.

Kata kunci: estetika, estetika wayang, dan estetika agama

\section{PENDAHULUAN}

Keindahan atau estetika (Bahasa Indonesia), estetic (Bahasa Inggris), berasal dari kata aesthanomai (Bahasa Yunani Kuno), artinya menikmati (Soetarno, 2001). Menikmati sebagai perilaku manusia, menghasilkan perasaan indah. Indah sesuatu yang la maujud (tidak tampak), sedang keindahan adalah manifestasinya.

Estetika, senantiasa ada dalam setiap budaya bangsa: kesenian, pertanian, peternakan, perdagangan, dan sebagainya. Realita dari setiap budaya bangsa tersebut, ujung-ujungnya pasti sampai kepada Tuhan. Wayang, sebuah kesenian sesuai dengan akar katanya "yang" (nenek moyang), digunakan dalam berbagai ritual: Bekakak, Ruwatan, Bersih Dusun, dan sebagainya untuk memuja roh nenek moyang sebagai fitrah manusia hamba Tuhan, dalam usahanya untuk mendapatkan kesembuhan, dan kemurahan sandang-pangan. Cocok tanam dalam usaha pertanian, dilakukan dengan prosesi awal menaruh takir (saji-sajian) di pojokpojok tanggul, untuk memuja dewa kesuburan agar terhindar dari segala penyakit dan hama. Si Blonyo dan Si Blunyah sebuah kerajinan dari boneka tanah atau kayu, ditaruh di atas dipet, meja, atau almari, digunakan untuk memuja dewa rejeki dalam usahanya untuk mendapatkan rupiah yang banyak, dan sebagainya.

Melihat kenyataan itu, maka tidak bisa dimungkiri bahwa estetika atau keindahan dalam pengertian bangsa Indonesia selama ini, keindahan-keindahan yang bisa memberikan pemahaman tentang Tuhan. Untuk orang Islam, jelas estetikanya adalah: innallaha jamiilun yuhibbul jamal: sesungguhnya Allah itu indah, dan suka pada keindahan (Departemen Agama, 1978): jamil (indah) itu dzatnya (tidak tampak), sedang jamal (keindahan) itu manifestasinya: larangan dan perintahnya: agama (yang tampak). Oleh karena itu, apabila konsisten, maka 
budaya dalam cabang apa pun mestinya harus senantiasa berjalan dengan estetika agama seperti bahasanya orang Islam: innashsholaati wanusuuki wamahyaaya wamaati lillaahirobbil 'aalamiin: sesunguhnya sholatku, ibadahku, hidupku, dan matiku hanya untuk Allah seru sekalian alam (doa iftitah dalam sholat). Tetapi tidak demikian kenyataan yang ada, wayang sebagai contohnya.

Wayang zaman para Wali dulu memang berjalan dengan estetika agama, walaupun hanya sebatas dakwah agar orang beribadah (da'wah li ibadah), . Hal itu sebagaimana tampak dalam membaca syahadat atau masuk Islam: "Bari gampil tanggapane amung maos kalimat syahadat nuli dadi muslim" yang berarti Mudah sekali bayarannya, hanya membaca kalimat syahadat kemudian masuk Islam (Abdullah, 1978, dari De Heligen Van Java ditulis D. A. Rinkes).

Wayang untuk sekarang ini berjalan nyaris dengan estetika lain, yakn pakem (gending, catur: bahasa yang diucapkan dalang, sabet: gerak-gerik wayang, dan sebagainya), bahkan juga uang, jabatan, wanita. Oleh karena itu, tidaklah aneh jika kemudian banyak ulama mengharamkan dan banyak orang mencercanya:

"Wayangku wis dudu lakuning urip kang sejati Wayangku wis kelangan adeg-adeg

Wayangku mung dinggo srana mungkaring hawa

nafsu Wayangku mung dinggo kudhung kedhok ing

karepan Wayangku keplantrang kombak kombul kerut

katut ing lakuning jaman".

"Wayangku sudah bukan tuntunan hidup

Wayangku sudah kehilangan ruh

Wayangku hanya digunakan untuk mengumbar nafsu

Wayangku hanya diperdaya oleh kehendak

Wayangku tidak punya arah yang jelas".

(Murtiyoso 1998, dari Dalang Goyang Gendheng Gendhung karya Subono).

Dengan kenyataan itulah, maka tulisan ini bermaksud untuk memberikan pemikiran atau jalan keluar bagaimana agar wayang sekarang ini bisa berjalan dengan estetika agama.

\section{ESTETIKA WAYANG DAN ESTETIKA AGAMA}

Wayang, adalah jenis kesenian tradisi yang disajikan oleh dalang dalam terminologi tunggal: mulai dari talu (gending-geding penghantar) sampai dengan tanceb kayon (adegan terakhir). Tuntunan wayang tersebut adalah pakem (gending, catur, sabet, dan sebagainya), dan bentuknya terputus (setelah selesai, sudah)
Dalam penyajian wayang tersebut, dalang duduk di atas panggung, penontonnya di atas kursi. Isi wayang adalah ajaran tentang "hong ilaheng" disampaikan dengan samar lewat cerita, boneka; gamelan, gending, catur, dan sebagainya. Ceritanya: Bima Suci, Dewaruci, Gatutkaca Lahir, dan sebagainya; bonekanya menggunakan: irah-irahan (mahkota), gelang, kalung, anting-anting; gamelannya menggunakan Slendro-Pelog; gendingnya karawitan; dan catur-nya banyak menggunakan bahasa Kawi: oom awignamastu, hong ilaheng, dan sebagainya.

\section{Penggabungan Estetika Wayang dengan Estetika Agama}

Agar wayang tersebut berjalan dengan estetika agama, bisa dilakukan dengan cara: pertama diysare'atkan, kedua disambungkan dengan ibadah, ketiga disambungkan dengan dakwah.

Disyare'atkan, maksudnya wayang yang ada (yang melanggar syare'at selama ini) dibuat sedemikian rupa menjadi tidak melanggar syare'at. Cara ini bisa dilihat seperti dilakukan oleh para Wali zaman Demak: wayang yang ada ketika itu bentuknya methok seperti manusia apa adanya (melanggar syare'at), diubah menjadi miring tidak seperti manusia apa adanya (tidak melanggar syare'at):

"Kacarita Kanjeng Sultan Syah Ngalam Akbar kasengsem marang kalangenan wayang, mangka ing kitab pekih kasebut karam, para Wali karsa nganggit wayang supaya ilang wujude gambar, raine wayang ginawe miring".

"Syahdan Sang Raja yang senang wayang, pada hal wayang itu haram, para Wali kemudian membuat wayang agar hilang bentuknya, muka yang ada dibuat miring".

(Murtiyoso, 2001, dari Kusumadilaga dalam Serat Sastra- miruda, 1981:160).

Kenyataan yang ada, apa yang telah diusahakan oleh para Wali tersebut tidak menjadikan wayang berjalan dengan estetika agama secara sempurna. Sebab, kecuali asali dari wayang itu sendiri masih tetap melanggar syare'at (sebagai cerita hayalan yang harus dijauhkan), juga bagian yang diubah (bentuknya) masih dalam khilafiah (perbedaan pendapat): ada yang menyatakan sudah tidak melanggar syare'at ada yang menyatakan masih melanggar syare'at. Karena cara tersebut tidak bisa menjadikan wayang berjalan dengan estetika agama secara sempurna, maka tidak akan dipilih dalam usaha ini.

Disambungkan dengan ibadah, maksudnya wayang yang ada selama ini disambungkan dengan syare'at tertentu, seperti: dzikir, sholat, puasa, dan 
sebagainya. Walaupun cara ini tidak memberikan jaminan terhadap benarnya syare'at wayang, tetapi karena disambungkan dengan ibadah, maka menjadikan wayang itu boleh dilakukan, atau paling tidak terampunkan. Sebab, bukan wayang itu yang dituju melainkan ibadah. Cara ini juga sudah dilakukan oleh para Wali pada zaman yang sama, yakni wayang yang ada ketika itu disambungkan dengan bai'at syahadat: hlaailaaha-illallaah, kemudian masuk Islam:

"bari gampil tanggapane amung maos kalimat syahadat nuli mlebu Islam".

"dengan mudah tanggapan atau bayarannya yakni dengan hanya membaca kalimat syahadat kemudian masuk Islam

(Abdullah, 1978, dari De Heligen Van Java ditulis D. A. Rinkes).

Hasil dari cara tersebut, karena ibadah (yang tersambung) itu sifatnya mandheg (tidak mengajak orang lain untuk mengajak), maka walaupun menjadikan wayang berjalan dengan estetika agama, tetapi tidak sempurna. Sebab, memungkinkan laju perjalanan wayang dengan estetika agama tersebut putus. Ketidak sempurnaan wayang berjalan dengan estetika agama itulah menjadikan Wali konon mengatakan "agar dakwah kelak disempurnakan oleh generasi mendatang" (bincang lepas dengan para da'i Jama'ah Tabligh, 2006). Karena cara ini juga tidak menjadikan wayang berjalan dengan estetika agama sempurna, maka juga tidak dipilih dalam usaha ini.

Disambungkan dengan dakwah, maksudnya wayang yang ada selama ini disambungkan dengan dakwah. Seperti disambungkan dengan ibadah, cara ini juga tidak memberikan jaminan terhadap benarnya syare'at wayang, tetapi karena disambungkan dengan dakwah, maka bagaimanapun wayang tersebut juga menjadi boleh dilakukan, atau paling tidak terampunkan. Sebab, memang bukan wayang itu yang dituju melainkan dakwah. Karena dakwah tersebut sifatnya bergerak: mengajak orang lain untuk mengajak (da'wah lidda'wah), maka cara ini akan menghasilkan wayang berjalan dengan estetika agama sempurna. Sebab, memungkinkan laju perjalanan wayang dengan estetika agama tersebut tidak putus. Oleh karena itu cara ini akan dipilih dalam usaha untuk menjadikan wayang sekarang ini berjalan dengan estetika agama.

\section{Menyambungkan Wayang dengan Dakwah}

Ada dua masalah dalam menyambungkan wayang dengan dakwah ini, pertama bagaimana cara menyambungkan wayang dengan dakwah, kedua dakwah dalam aplikasi apa yang akan dipilih dalam usaha ini. Menyambungkan wayang dengan dakwah, selama ini belum pernah dilakukan oleh siapa pun termasuk para Wali. Oleh karena itu, bagaimana menyambungkan wayang dengan dakwah tersebut juga tidak diketahui. Namun demikian, cara tasykil yang biasa digunakan oleh Jama'ah Tabligh untuk menyambungkan bayan dengan dakwah, akan coba diadopsi untuk menyambungkan wayang dengan da'wah ini.

Dakwah, pada umunya tidak ada khilafiah tentang pengertian baik harfiyah adalah mengajak, maupun istilahnya yakni menghasung atau mengajak manusia untuk taat kepada Allah dengan cara melakukan ajarannya (Effendi, 1978:14). Akan tetapi, kenyataan aplikasi yang ada di sana-sini berbeda. Ada dakwah dalam aplikasi kultural (banyak dilakukan oleh kalangan Muhammadiyah), dakwah dalam aplikasi spiritual (banyak dilakukan oleh kalangan Nahdlatul Ulama), dakwah dalam aplikasi sabilillah atau lengkapnya khuruj fii sabiilillah (dilakukan oleh kalangan Jama'ah Tabligh), dan sebagainya. Oleh karena dakwah tersebut aplikasinya berbeda-beda, maka dipilih salah satu. Adapun dakwah yang dipilih dalam usaha ini adalah dakwah dalam aplikasi khuruj fii sabilillah (seterusnya dalam tulisan ini disebut dengan: "dakwah" saja). Dipilihnya dakwah dalam aplikasi tersebut, sebab pola kerjanya lebih jelas, yakni keluar tiga hari, empatpuluh hari, empat bulan, dan sebagainya.

\section{Konsep dan Aplikasi Tasykil}

Tasykil yang biasa digunakan oleh Jama'ah Tabligh untuk menyambungkan bayan dengan dakwah, bisa dilihat dalam ijtima' atau perkumpulan yang dilakukan setiap Kamis malam seperti di Masjid Al-Ittihad Yogyakarta, Masjid Jami’ Kebon Jeruk Jakarta, Pesantren Temboro Magetan, dan sebagainya. Prosesi tasykil dalam ijtima' tersebut, mula-mula dilakukan bayan terlebih dulu, baru kemudian tasykil berikut dakwah.

Bayan (Bahasa Arab) artinya keterangan. Bayan ini bentuknya pengajian: satu orang mubayin (orang yang bayan) berdiri atau duduk di lantai atas (trap atau kursi), sedang mustami' (orang yang mendengarkan bayan) duduk iftiros (duduk timpuh: kedua telapak kaki ditindih pantat) di lantai bawah dengan tertib berdesakdesakan. Isi bayan: tentang pentingnya dakwah-disampaikan dengan jelas: banyak mengutip ayat-ayat Al-Qur'an dan Al-Hadits secara langsung. Setelah bayan selesai, dilanjutkan tasykil.

Tasykil (Bahasa Arab) artinya membentuk; membentuk jama'ah keluar dakwah. Untuk bisa membentuk jama'ah keluar dakwah tersebut, yang dilakukan adalah mengajak secara terang-terangan atau secara langsung kepada mustami untuk keluar dakwah. Tasykil ini biasa dilakukan oleh mubayin itu sendiri atau tim tasykil yang telah ditunjuk. Mustami' yang ada kesiapan untuk dakwah (tasykilan) dicatat, dan dikeluarkan untuk dakwah sesuai dengan waktu yang diberikan.

Dakwah artinya mengajak; mengajak orang lain untuk melakukan dakwah juga (da'wah lidda'wah). Lama dakwah tiga hari, empatpuluh hari, atau empat 
bulan, bahkan bisa juga setahun. Dakwah ini diawali dari bayan hidayah (pembekalan), yakni bayan atau keterangan-keterangan yang isinya tentang tertib dakwah: tidak boleh menyentuh politik, khilafiyah (perbedaan pendapat), derma (sumbangan), 'aib masyarakat (kejelekan masyarakat), dan sebagainya. Bayan hidayah ini diberikan oleh orang yang telah ditunjuk dalam musyawarah Jama'ah Tabligh. Setelah selesai dakwah sesuai dengan waktu yang telah direncanakan, kemudian diberi bayan tangguh (pesan-pesan setelah selesai dakwah), yakni bayan atau keterangan-keterangan yang isinya tentang tertib setelah keluar, di antaranya: agar setibanya di rumah tetap dakwah kepada orang lain: keluarga, dan tetangga kanan kiri dengan cara silaturrahim (dakwah maqomi), dan setelah nisab atau waktunya (1 bulan) agar keluar lagi dengan cara yang sama. Bayan tangguh ini juga diberikan oleh orang yang telah ditunjuk dalam musyawarah Jama'ah Tabligh. Demikian dakwah dilakukan dengan cara berulang-ulang atau sambungmenyambung sampai waktu yang tidak terbatas.

Aplikasi tasykil dalam usaha menyambungkan wayang dengan dakwah ini, mula-mula disajikan wayang terlebih dulu, baru kemudian tasykil, dan terakhir dakwah.

Wayang disajikan sebagai analogi dari bayan. Karena disajikan sebagai analogi dari bayan, maka dibuat sedemikian rupa seperti bayan: disajikan oleh dalang mulai dari talu sampai dengan tanceb kayon. Dalangnya duduk di lantai atas (trap), penontonnya duduk iftiros di lantai bawah. Isi wayang berupa ajaran tentang pentingnya usaha dakwah - disampaikan dengan jelas: banyak mengutip ayat $\mathrm{Al}$ Qur'an dan Al-Hadits secara langsung baik lewat cerita, boneka, gamelan, gending, catur, dan sebagainya.

Sebagai contoh, untuk cerita Bimasuci dibuat sedemikian rupa menjadi Bima Da'wah, Dewaruci menjadi mBabar Ma'rifat; Gatutkaca Lahir menjad Gatutkaca Tarbiyah, dan sebagainya. Boneka dibuat menggunakan pakaian muslim, dengan memakai serban, jubah, celana blunci (tidak panjang tidak pendek), tanpa kumis, memanjangkan janggut, dan sebagainya. Untuk gamelan dibuat dengan banyak menggunakan terbang, rebana, dan bedhug, sedangkan gending berupa gending sholawatan, dan sebagainya. Untuk catur, kecuali banyak mengutip ayat Al-Qur'an dan Al-Hadits, juga diusahakan untuk banyak menggunakan bahasa agama seperti: assalaamu'alaikum, astaghfirullaah, bismillaah, baldatun thoyyibatun warobbun ghofuur, dan sebagainya.

Setelah pertunjukan wayang selesai, kemudian dilakukan tasykil. Tasykil, atau usaha mengajak penonton untuk dakwah ini, bisa dilakukan oleh dalang itu sendiri dan atau pengrawit yang telah ditunjuk. Penonton yang ada kesiapan untuk dakwah (tasykilan) dicatat, kemudian dikeluarkan untuk dakwah sesuai dengan waktu yang diberikan - digabung (bersama-sama) dengan Jama'ah Tabligh yang ada (yang bergerak) di masjid desa sekitar wayang.
Dakwah, atau keluar tiga hari, empat puluh hari, atau empat bulan, diawali dari bayan hidayah, diakhiri dengan bayan tangguh. Masing-masing baik bayan hidayah maupun bayan tangguh, diberikan oleh orang yang telah ditunjuk dalam musyawarah dalam Jama'ah Tabligh. Dengan dikeluarkannya tasykilan penonton wayang untuk da'wah tiga hari, empat puluh hari, atau empat bulan-digabung dengan Jama'ah Tabligh yang ada di masjid desa sekitar wayang tersebut, maka berarti sambunglah wayang ini dengan da'wah.

\section{Gabungan Wayang dan Dakwah}

Wayang, setelah disambungkan dengan dakwah, berubah jenisnya menjadi kesenian dakwah yang disajikan oleh dalang dalam terminologi ganda: wayang, tasykil, dan dakwah, tuntunannya agama, bentuknya sambung (tidak terputus). Dalam penyajian wayang tersebut, dalang duduk di lantai atas, penontonnya duduk iftiros di lantai bawah. Isi wayang: ajaran tentang pentingnya dakwah - disampaikan dengan jelas lewat cerita, boneka; gamelan, gending, catur, dan sebagainya. Ceritanya: Bima Dakwah, mBabar Ma'rifat, Gatutkaca Tarbiyah, dan sebagainya; bonekanya menggunakan pakaian muslim: serban, jubah, celan blunci, memotong kumis, memanjangkan janggut; gamelannya banyak menggunakan: bedhug, terbang dan rebana; gendingnya sholawatan; dan caturnya menggunakan bahasa agama: assalaamu'alaikum, astaghfirullaahal, bismillaah, baldatun thoyyibatun warobbun ghofuur, dan sebagainya. Setelah wayang selesai, kemudian dilakukan tasykil.

Tasykil atau mengajak penonton untuk dakwah, dilakukan oleh dalang atau pengrawit usai wayang. Penonton yang ada kesiapan dicatat, kemudian dikeluarkan untuk dakwah sesuai waktu yang diberikan - digabung dengan Jama'ah Tabligh. Dakwah diawali dari bayan hidayah, diakhiri dengan bayan tangguh. Masing-masing baik bayan hidayah maupun bayan tangguh, diberikan oleh orang yang telah ditunjuk dalam musyawarah Jama'ah Tabligh. Demikian dakwah dilakukan dengan cara berulang-ulang atau sambung-menyambung sampai waktu yang tidak terbatas.

\section{SIMPULAN}

Agar wayang berjalan dengan estetika agama, wayang tersebut harus disambungkan dengan dakwah. Untuk menyambungkan wayang dengan dakwah, digunakan tasykil, yakni mengajak secara langsung kepada penonton untuk dakwah usai wayang.

Wayang setelah disambungkan dengan dakwah, berubah jenisnya menjadi kesenian dakwah, terminologinya ganda: wayang, tasykil dan dakwah, tuntunannya agama, dan bentuknya sambung. Menyambungkan wayang dengan dakwah agar wayang berjalan dengan estetika agama, hendaknya tidak berhenti 
pada pemikiran saja, tetapi benar-benar diujutkan dalam kenyataan, dan hasilnya perlu ditindak lanjuti.

\section{DAFTAR PUSTAKA}

Abdullah, 1978. "Simbolik dalam Dewaruci dan Psikologi Jung". Ceramah Pusat Pewayangan, 3 Agustus 1971, di Teater Arena P.K.D. Taman Ismail Marzuki Jakarta.

Departemen Agama Republik Indonesia, 1985. Qur'an dan Terjemahannya. Proyek Pengadaan Kitab Suci Al-Qur'an

Effendi, Zarkasi, 1977. Unsur Islam dalam Pewayangan, Bandung: PT.AlMa'arif.

Murtiyoso, Bambang, 1998. "Perkembangan Pakeliran Dewasa Ini dan Upaya Pembinaannya" Makalah disampaikan pada Sarasehan Dalang dan Seniman Magelang.

Murtiyoso, Bambang, 2001. "Seni Pedalangan Sebagai Penyampaian Pesan". Kumpulan Essay Bambang Murtiyoso, 1997-2001.

Soetarno, 2001. "Bahan Ajar Estetika Pedalangan I". Sekolah Tinggi Seni Indonesia (STSI) Surakarta. 